\title{
Descriptive Evaluative Study on the Implementation of Online Learning During the COVID-19 Pandemic in the Courses of Guidance and Counseling Profession
}

\author{
I Wayan Dharmayana* and Anna Ayu Herawati
}

\author{
Guidance and Counseling Study Program, University of Bengkulu \\ *Corresponding author. E-mail: dharmayana@unib.ac.id
}

\begin{abstract}
In the future, online learning should be an essential part of integrating every education unit in Indonesia, especially in higher education, into the learning system. The COVID-19 pandemic's new normal era has become an important momentum for the need for online learning using information and communication technology, which adapts the social distance policies of the government to preserve distance and reduce face-to-face learning activities. During the COVID-19 pandemic, lectures in the Guidance and Counseling Technical Courses were often performed online using learning system management applications (both related to preparation, execution, and assessment) in the form of Google-Classroom combined with zoom cloud meeting and practically meet-google face-to-face learning applications. This research aims to identify and assess the implementation of online learning in this course, using a survey approach, using a self-report questionnaire prepared to evaluate the efficacy of online learning based on the LED (E-learning Interaction Design) system. Students who took the course were the subjects of this study, totaling 60 individuals, consisting of Class 6A, 30 students, and Class 6B, 30 students). The data was analyzed and qualitatively interpreted using descriptive statistics. The results showed that there was an increase in the efficiency of intense student participation, learning discipline, and learning satisfaction and mastery of learning results. For further reflection, many reinforcing and inhibiting variables during learning are defined and addressed and followed up in order to more efficiently integrate online learning in the future.
\end{abstract}

Keywords: Online learning, Google classroom and meet, New normal COVID-19, Zoom cloud meeting.

\section{INTRODUCTION}

If this technology is used in a mixed campus environment or fully online, web-based learning technology has a significant effect on the learning environment in higher education. In terms of learning outcomes for students, online learning can equal and potentially outperform conventional classroom-based learning in some cases. Even so in online learning, students still face the risk of bad academic results [1].

While success in online learning depends to some extent on the characteristics that students bring to the online learning environment [2], it is also clear that educators as teaching designers may contribute to the success of students through the adoption of learning designs aimed at promoting online learning media engagement, participation and communication [3]. The need to find realistic connections between research on student academic engagement and the design of successful online learning seems to be linked to many of the current difficulties.

Effective learning can be encouraged and promoted by how online learning can be done, especially using Internet technology. More precisely, it is possible to achieve successful online learning by integrating it with conventional face-to-face learning activities, with a focus on sound technology-based pedagogy that combines the concepts of the theory of engagement. Basically, effective learning refers to increasing the relation between effective learning processes (such as communication, engagement, involvement, accountability) and learning outcomes and goals (higher-order thinking, critical thinking, and problem-solving skills). A literature review shows that Internet learning provides students and teachers with enticing opportunities through interactive, project-based, and authentic experiences that are not accessible through conventional face-toface teaching methods [4].

Several countries have adopted social distancing aimed at minimizing interactions between individuals in the wider community, where people might be infected but have not been detected and thus have not been isolated [5]. Another perspective notes that if social distance is considered inadequate in the battle against COVID-19, then social containment ('social containment') on a large scale is what is needed [6]. Social containment is a government intervention that is deliberately intended to minimize personal 
interactions in the entire population, city or area, with the exception of limited interactions to ensure essential supplies [5]. Indeed, as some experts have pointed out if preventive policies fail and social distancing initiatives cannot be sustained before a vaccine is available, the next best option is to use interventions that minimize mortality and avoid excess infection [7].

Online learning needs to be improved by higher education during the Work from Home (WFH) era. For the last few years, online learning has been a demand in the world of education [8]. Closed and understood as a conventional model, face-to-face learning is considered so that better learning facilities are required by the use of information technology [9]. Coordination between both parties is very likely in the introduction of online learning [10]. Higher education would be created by online learning if a new learning environment is created [11]. Online learning, which is not organized, is not casual, as happens in daily life when people access the internet [12]. Experts point out that all resources must be dedicated to the development by 2025 of online education that is currently taking place in the mainstream [13].

It became a necessity for any higher education lecturer during the WFA era to plan and coordinate online learning so that curriculum specifications could be completed according to the predetermined academic calendar.

Several research findings related to online learning report that in contrast to face-to-face lectures, students typically have a positive attitude towards online learning [14]. An alternative to a faceto-face college education is online learning [15]. Several studies have shown that online learning tests yield considerable efficacy [16]. In this situation, by first submitting written procedures, the lecturer has the task of evaluating student writings. Corrections are made through a peer-review process before being reviewed by lecturers in the sense of introducing a student-centered educational model. By comparing the first text and the last text, assessment is carried out to increase the quality of writing. Other research confirms that students are happy that online learning has been implemented [17].

For the help of online learning, various platforms may be used [18]. There have been many online courses, amongst other items, that continue to grow in higher education [19]. In each university, like Bengkulu University, online learning is massively conducted with different variations. It was a surprise that educators were shocked to start learning using ICT media to find ways to perform lectures without lowering the quality of learning, including the
Guidance and Counseling Study Program, as required by the curriculum of each study program.

During the COVID-19 pandemic, online learning using virtual class management with the Google Classroom application was carried out in the Guidance and Counseling Professional Courses, enabling students to participate in full via the forum chat panel, where students could access study materials, read events, and ask and answer multidirectional questions that enable students to actively chat. Lecturers also use classwork facilities to offer assignments, students submit assignments, and lecturers may review and provide input on assignments submitted. And the value panel is used to gather grades that have been completed by students related to tasks, formative tests, and summative tests. The Zoom cloud meeting application is also used by lectures and Google, which is a virtual face-to-face facility via video conference, is also used.

The aim of this research is to identify and analyze the on-line learning implementation of the Guidance and Counseling Professional Course in the Guidance and Counseling Study Program, so that it becomes a material for reflection and progress on the potential implementation of online learning.

The research question is: (1) How do I use the Google Classroom learning framework program to incorporate online learning for the Professional Guidance and Counseling Course? (2) How do I use a virtual face-to-face application, Zoom Cloud Meeting, and Meet Google to introduce online learning for the Technical Guidance and Counseling Course? (3) Why are students involved in online learning programs in the course of educational guidance and counseling? (4) How are students happy with engaging in the Guidance and Therapy Technical Course in online learning? (5). What are the challenges and help factor in the work of the Advice and Therapy Technical Course in online learning?

During the COVID-19 2020 era, the learning design used in online learning uses a procedural framework developed by Czerkawski \& Lyman [1] with E-Learning Engagement Design (LED) as a procedural framework that incorporates a model of teaching design that emphasizes best practices for engaging online learning students. It is also not viewed as a new paradigm, but as a synthesis of the current research literature, so that an easy-to-apply model for practice can be used by an online teacher. The success of online learning can be measured by student engagement in online learning. The higher the participation of students, the better the template for learning. 
In the Guidance and Therapy Technical Course, online learning has passed through all four phases in the Directed framework, with the exception of stage 4 related to assessing the efficacy of online learning. An overview of the criteria for materials and practices promoting professionalism in guidance and therapy was carried out in stage 1 . Learning goals were formulated in stage 2 in the form of learning results to be achieved, including professional expectations that must be met. In Stage 3, the design and conditioning of online learning using the Google Learning Management Framework for the classroom, which includes (1) discussion space with the forum panel where students can communicate (multidirection) with each other, design task completion including contact with lecturers, (2) class assignments to include assignments, high-level questions, formative exams, summative exams with a defined deadline, encourage students to be disciplined in an organized manner, and a form is available to assess each, (3) The grading panel may be used to provide input to students in order to determine and summarize each assigned class assignment. There is also an option of media in Stage 3 to remotely connect face-to-face using video conferencing facilities, at this stage there are 2 apps used namely Zoom Cloud Meeting and Meet-Google.

\section{METHODS}

In the context of an Evaluative Overview Analysis of Online Learning during the Covid 19 pandemic, this report is survey research. In the Technical Guidance and Therapy course during the Covid 19 pandemic, descriptive means explaining phenomena related to online learning. Evaluative means measuring the efficacy of the online learning application during the duration of Covid-19, including the supporting and inhibiting factors.

Online Learning uses four phases of the LED (ELearning Engagement Design) framework method, namely (1) identifying student needs, (2) formulating learning goals, (3) planning an online learning environment, including choosing the online media to be used, (4) conducting a summative evaluation of learning outcomes. An evaluation of the efficacy of online learning is the fourth level. This report is a follow-up to the final process to be carried out, namely the assessment of the efficacy of online learning.

This study was performed with 60 Semester VI Guidance and Counseling Study Program members, including all students who took the Technical Guidance and Counseling Course, consisting of Class A 30 and Class B 30 individuals who replied to the Google form questionnaire. Student Primary data is collected directly from students involved in the lecture and current documents on the Google Classroom forum slot and class assignments and grades to see the tasks and outcomes of students' formative and summative activities.

In order to show the readiness of online learning implementation during the COVID-19 pandemic, the data collection strategies used were (1) Self Report Questionnaire. This questionnaire seeks to disclose the impression of students during online lectures and how they are engaged in online lectures, and student satisfaction with the execution and assess what has gone well with the execution of online learning and what is necessary to study in the professional course of Guidance and Counseling, (2) Documents to gather documentation in the form of interactive forum panel discussions, the outcomes of class assignments to see the tasks completed, and in-class, formative and summative student engagement assignments submitted to the Google Classroom. The benefits and drawbacks and the supporting and inhibiting factors then assessed can also be evaluated by lecture recordings using the zoom cloud meeting facility.

Quantitative analysis, namely descriptive statistics consisting of frequency, descriptive, t-test in the IBM SPSS Version 22 Software, is used to answer each research query. Every quantitative data is qualitatively interpreted.

\section{RESULTS AND DISCUSSION}

In the Guidance and Therapy Study Program, 60 students of the 6th semester, consisting of 30 individuals in Class A and 30 in Class B, were characteristic of research subjects. Subjects consisted of 16.67 percent male, 88.33 percent female. The subject's residency during the Covid 19 pandemic was 30 percent in urban areas, 20 percent in suburban areas, 48.33 percent in rural areas, and 1.67 percent in remote villages.

It can be stated that 82 percent of the father's education and 80 percent of the mother's education have a high school background or lower, even five to six percent of their parents did not complete elementary school, the condition of the parents of the subject. 19\% hold a bachelor's degree or master's degree.

Communication and IT equipment that can promote access to knowledge through the internet, including in the form of desktop computers, laptops, iPads, gadgets/smartphones, as well as support for the availability of internet quotas and internet hotspots available for online learning, are the essential equipment that students should have in online learning.

The conditions of student-owned online learning facilities suggest that although using a 
laptop/notebook is the optimal online learning condition, most students use smartphones, $90 \%$ of the equipment owned was their own, $10 \%$ borrowed from friends and shared with relatives and fathers.

During the Covid 19 pandemic, most (50\%) claimed that the availability of internet quotas for students was adequate and very sufficient to take online lectures, and some stated that they were inadequate. At the time of the pandemic, much of the students' internet quota $(74 \%)$ was personal, $26 \%$ used the campus internet network $(9 \%)$, free Wi-Fi in public areas $(6 \%)$, and used the internet at home $(11 \%)$.

The reliability of the Internet signal during the Covid 19 pandemic in the position or location where the students received online learning. The majority (75\%) ranged from good enough or stable enough to very good and very stable. This will definitely be the enabling capacity for most students during the COVID-19 pandemic to be able to attend online lectures. Another $25 \%$ also encounter network limitations and have to find a place and time to get a strong and reliable signal from the network. The approach to solving issues with poor internet signals or blackouts for students is that $73 \%$ try to find a location with an internet network, and $3 \%$ prefer not to engage in the course.

After the outbreak of the Covid 19 outbreak, all learning activities must be transferred online with the provision of social distance, by using the face-to-face learning rooms available (virtual meeting). Lecturers must strive for new alternatives to execute lectures to ensure that the learning outcomes stated in the curriculum are achieved. The Google classroom framework is one of the virtual learning spaces available that is readily accessible by having enough memory. 73.33 percent said that using Google classroom, online learning claimed that the program was really simple to implement.

The ease that students feel, especially when using the features in the Google Classroom application, namely $49.47 \%$ of students using the feature to download study materials and upload completed assignments and tests, $29.47 \%$ of students use discussion forums to study groups and collaborate to complete lecture assignments, $13.68 \%$ to see the value of each assignment and test. This ensures that most learners take advantage of the learning opportunities available in the Google classroom and take advantage of the facilities to ensure that tasks and exams are provided with certainty.

The results of student reflections on the efficacy of learning activities using google classroom show that the majority $(43 \%)$ of students reflect that learning through google classroom will train discipline within a predetermined deadline to complete tasks, $23 \%$ of students said that learning through Google classroom also becomes more productive when combined with face-to-face" Google Classroom allows interaction with fellow students, between students and lecturers, and between students and learning resources, it can also facilitate the completion of assignments in groups "Google Classroom facilitates interaction with fellow students, between students and lecturers, and between students and learning resources, it can also facilitate the completion of group assignments.

Student responses indicate that 95 percent said they were very happy and comfortable, happy and comfortable, and quite happy and comfortable in terms of the fun/convenience of engaging in online learning with the google meeting application. This illustrates that virtual face-to-face meetings are felt to be able to replace face-to-face meetings held so far using the Google Meet application because there are no other alternatives and they are felt to be secure to escape transmission of Covid 19 (see Figure 1). This reaction is in line with the response to student participation in Google Meeting sessions, showing that 93.33 percent of students said they were really interested in learning activities.

Student responses indicate that 95 percent said they were very happy and comfortable, happy and comfortable, and quite happy and comfortable in terms of the fun/convenience of engaging in online learning with the google meeting application. This demonstrates that virtual face-to-face meetings are felt to be able to replace face-to-face meetings held so far using the Google Meet application because there are no other alternatives and they are felt to be secure to prevent transmission of Covid 19 (see Figure 1). This reaction is in line with the response to student participation in Google Meeting sessions, showing that 93.33 percent of students said they were really interested in learning activities.

From the enjoyment and comfort of students, student engagement, and student satisfaction in taking online lectures using zoom cloud meetings, the quality of online learning with the use of Zoom meetings can also be seen. Eighty-seven percent of students indicated that using zoom meetings they were very relaxed/happy, comfortable and happy and quite comfortable learning.

The intensity of student participation in online learning using zoom cloud meetings; $93,33 \%$ of students said they were very interested in online learning using zoom meetings until they were quite involved, and $89.33 \%$ said they were very content, pleased, and quite satisfied with zoom meeting learning.

More than 95 percent of student involvement in online learning events showed that they were active 
and really engaged; $96.55 \%$ in virtual face-to-face activities (virtual meetings), $96.56 \%$ in chat forums, 100 percent in reading activities and resumes of learning materials, 100 percent in deadline assignments, 96, 35\% in virtual presentations On average, $5 \%$ of students reported not being involved.

Student evaluation of online learning activities for lecturers, including (1) the efficacy of online learning management, (2) clarification and systematic presentation of lecturers, (3) the capacity of lecturers to promote interest in learning, (4) the efficient use of time in learning, (5) the readiness of teachers to assist students, and (6) this shows that $95.69 \%$ gave good and very good evaluations, $8.62 \%$ graded them as poor and very bad with pace in giving grades and useful feedback.

Student quality assessment of online learning Lecturers in the Technical Guidance and Counseling Course, which includes the following aspects: (1) clarification of learning goals or outcomes, (2) preparation and structure of lecture content, (3) load of courses, (4) complete participation of students in lectures, (5) interactive learning methods carried out, 6) authentic learning appraisal and according to what has been learned, $95.98 \%$ of students scored good and very good on average, $4.02 \%$ rated bad.

Table 1. Descriptive Statistics of Learning Outcomes Before and After Online Learning

\begin{tabular}{|c|c|c|c|c|c|}
\hline & $\mathrm{N}$ & Min & Max & Mean & Dev.S \\
\hline Offline Mastery & 60 & 60 & 85 & $\mathbf{7 3 . 8 0}$ & 6.412 \\
\hline $\begin{array}{c}\text { Online Mastery } \\
\text { Valid N }\end{array}$ & 60 & 65 & 90 & $\mathbf{7 9 . 4 7}$ & 5.646 \\
\hline \multicolumn{2}{|c|}{$\mathbf{t = \mathbf { - 1 2 . 5 7 1 }}$} & $(\mathbf{p}<\mathbf{0 . 0 5}\}$ \\
\hline
\end{tabular}

Table 1 shows that, relative to the situation at the end of the semester (learning results after half a semester), the average student master's degree in the pre-pandemic Guidance and Counseling Career Course (near the middle of the semester) shows a substantial difference with $t=-12,571(\mathrm{p}<0,05)$. This result demonstrates that while the mastery of students is both in the Positive range, the average mastery of the Online Learning Guidance and Counseling Career Course is higher $($ Mean $=79.47)$ than the mastery of students before the mostly faceto-face pandemic. $($ Mean $=73.80)$ face.

\section{Discussion}

While the students of the Guidance and Counseling Professional course were not prepared to participate in online learning when the Covid-19 pandemic was not ready, they nevertheless adhered to the concept of E-Learning Interaction Design (LED) as a procedural framework to promote student participation. With the 79.47 student mastery level (good category), online participation in the Guidance and Counseling Career course running well, marginally increased compared to when offline learners before the pandemic, which was 7380 (in the category good, too).

The mastery achievement of the above learning outcomes is of course, connected to how the online learning phase of the participating learning system is applied in the Professional Lectures Guidance and Therapy, which begins with (1) assessment of learning needs; evaluation of student success and preparation to incorporate online learning; (2) reaffirmation of learning outcomes according to the RPS to be run; (2) reaffirming learning outcomes according to the RPS to be carried out, (3) planning a suitable learning environment; creating strategies for interaction and collaboration, designing online feedback facilities, preparing e-learning materials, selecting learning media and tools, preparing materials and tasks either by the use of those accessible on the internet (by use) or by innovation(4) evaluating the results of learning and evaluating the efficacy of online learning.

The usefulness of online learning in the Google Classroom course as a learning management system enables students to be better handled as a learning group. Learning events, a website, a collaborative learning space where conversations can be monitored and knowledge exchanged or shared (downloaded and uploaded) between students and between students and lecturers from different sources of learning materials. There are also Classwork Room facilities in the Google classroom application, where lecturers can assign assignments that students can accept and upload assignments according to predetermined deadlines. All students can also conveniently use the application so that all students 
can attend lectures such as the face-to-face lectures that were taken before the pandemic of Covid 19. This situation illustrates the satisfaction of student participation in all online learning activities that are effective in achieving learning outcomes for the course.

This finding follows Pike, Kuhand, and McCormick's study results [1], emphasizing that "...participatory learning community activities are strongly correlated with active lecturer-student interactions". The correlation between the learning community's involvement and the incorporation of various interactions and a strong degree of higherorder thought that affects engagement and academic success. Membership of the learning group increases the interest of students, which in turn contributes to some beneficial results in education.

Using the virtual face-to-face program Zoom Cloud Meeting and Meet Google, the implementation of online learning for the Professional Guidance and Counseling Course also runs very efficiently to keep students engaged in learning, most students claim to be engaged in virtual face-to-face learning activities, although some students can not completely participate in virtual meetings due to internal learning activities. Several learning theories in Experience Learning Theory and Engagement Theory [4] may also clarify these findings.

The usefulness of virtual meetings enables students to experience learning that is actively engaged, self-initiated, and is incorporated and expressed in the information gained. Digital meetings often include intense involvement of students, increased levels of teamwork, interactivity, and participation, including all people participating in the team and responsible for their own learning experiences, involved in cognitive and social processes [4].

The findings of this study also showed that in the Guidance and Therapy Career course, the participation of most students in online learning activities. The efficacy of online learning, which significantly influences the learning outcomes that have been determined, is very supportive of this scenario. This finding is consistent with the student satisfaction survey of online learning events, which indicates that 96.55 percent were satisfied and very satisfied; In virtual face-to-face activities, 91.38 percent in the Chat Forum, $89.65 \%$ in reading activities and resume learning materials, 90.83 percent in deadline tasks, $89.65 \%$ in virtual presentation activities, $98.22 \%$ in exam-taking activities and $94.83 \%$ in learning outcomes activities. A total of $4 \%$ of students said they were not happy until they were pleased.

\section{CONCLUSIONS}

In the Guidance and Counseling Career course, student satisfaction with engaging in online learning activities is often measured by promoting and inhibiting factors in ongoing online learning. Although the data show that barriers to the introduction of student online lectures are still identified by each seeking a solution to overcoming barriers such as finding an ideal internet network so that students can achieve learning results in a better category.

In the future, the aspirations of students in online learning are (1) online lecture materials organized in various ways of presentation (such as texts, video, photographs, interactive media so that they are preserved, (2) learning media is good for independent and collaborative learning, and combined with virtual meetings using either the zoom application or Google meetings are successful, (3) all lecture material may be tailored to the needs of professional development advice and therapy", "all useful or necessary and quite important. "It is really important for me to support my learning activities during my counseling career. The student said, "Illustrations of material in the form of video tutorials, posted inspiring videos that can encourage and motivate learning." A counselor or instructor of advice and therapy conducts activities professionally and may not deviate from their duties. Guidance and Counseling Profession materials will make me more prepared to carry out my profession online as well as offline in the future. 'I understand more thoroughly the different types of professional services in the field of guidance and therapy and are better able to explain different modes of service by presenting both online and offline, (4) a reliable internet network, and appropriate internet cap, both in terms of their aims, components and values as well as the complexities of activities. Of course, the aspirations of these students are realistic and when undergoing online learning, there are some students who face challenges because of that. After all, when uploaded tasks are documented late in the Google classroom, they are disconnected and feel delays in reacting to tasks and inconvenience. Android mobile phones, computers, course books, and a strong network are the significant equipment that is felt to enable online lectures. The online learning system will operate smoothly if the four systems are met. Students complete tasks, (6) social learning is also important to pay more attention to engaging students in learning, (7) it is important to use Google classroom discussion forums as much as possible to sustain relationships between students and lecturers and between students, (8) Virtual meetings remain an important part of the online learning process through google meetings and zoom because 
they can inspire and promote learning, it's just that not all students can access good signals to virtual meetings. Online Guidance and Counseling technical lectures are ideal for the future, so that more interesting learning technologies can be applied to improve lecture implementation.

\section{REFERENCES}

[1] Czerkawski, B. C. and Lyman, E. W. (2016). An Instructional Design Framework for Fostering Student Engagement in Online Learning Environments. TechTrends, vol. 60, no. 6 , pp. 532-539.

[2] Leeds, E., Campbell, S., Baker, H. R., Ali, D., Brawley, \& Crisp, J. (2013). The impact of student retention strategies: An empirical study. International Journal of Management in Education, 7(1-2), 22-43.

[3] Robinson, C. C., \& Hullinger, H. (2008). New benchmarks in higher education: Student engagement in online learning. Journal of Education for Business, 84(2) pp 101-109. doi:10.3200/JOEB.84.2.101-109.

[4] Damoense, M. Y. (2003). Online learning: Implications for effective learning for higher education in South Africa. Australas. J. Educ. Technol., vol. 19, no. 1, pp. 25-45.

[5] Smith, A. W., \& Freedman, D. O. (2020). Isolation, quarantine, social distancing, and community containment: a pivotal role for old-style public health measures in the novel coronavirus (2019-nCoV) outbreak 2020. Journal of Travel Medicine.

[6] Long, N. J. (2020). From social distancing to social containment: reimagining sociality for the coronavirus pandemic. Medicine Anthropology Theory.

[7] Handel, A., Miller, J., Ge, Y., \& Fung, I. C.H. (2020). If containment is not possible, how do we minimize mortality for COVID19 and other emerging infectious disease outbreaks? Medrxiv: The preprint Server for Health Sciences.

[8] He, W., Xu, G., \& Kruck, S. (2014). Online IS Education for the 21st Century. Journal of Information Systems Education.

[9] Panigrahi, R., Srivastava, P. R., \&, Sharma, D. P. R. (2018). Online learning: Adoption, continuance, and learning outcome-A review of literature. International Journal of Information Management.

[10] Tolsteneva, A. A., Gruzdeva, M. L., Katkova, O. V., Prokhorova, O. N., \& Lagunova, M. V. (2019). Organizational and Technical Conditions for the Implementation of
Educational Programs of the University Using Open Online Courses of the National Platform for Open Education. In Lecture Notes in Networks and System. Switzerland: Springer.

[11] Huda, M., Maseleno, A., Teh, K. S., Don, A. G., Basiron, G., Jasmi, K. A., Ahmad, R. (2018). Understanding Modern Learning Environment (MLE) in the Big Data Era. International Journal of Emerging Technologies in Learning (IJET).

[12] Holland, A. A. (2019). Effective principles of informal online learning design: A theorybuilding metasynthesis of qualitative research. Computers \& Education.

[13] Palvia, S., Aeron, P., Gupta, P., Mahapatra, D., Parida, R., Rosner, R., \& Sindhi, S. (2018). Online Education: Worldwide Status, Challenges, Trends, and Implications. Journal of Global Information Technology Management.

[14] Aghajani, M., \& Adloo, M. (2018). The Effect of Online Cooperative Learning on Students' Writing Skills and Attitudes through Telegram Application. International Journal of Instruction.

[15] Shepherd, R. P. (2018). Digital Writing, Multimodality, and Learning Transfer: Crafting Connections between Composition and Online Composing. Computers and Composition.

[16] Baldwin, S., Ching, Y.-H., \& Hsu, Y.-C. (2018). Online Course Design in Higher Education: A Review of National and Statewide Evaluation Instruments. Journal of Computing in Higher Education.

[17] Maha, E. T., Shazia, S., \& Jehan, A. (2016). Using gamification to develop academic writing skills in dental undergraduate students. European of Journal Dental Education.

[18] Bensalem, E. (2018). The Impact of Whatsapp on EFL Students' Vocabulary Learning. Arab World English Journal (AWEJ).

[19] King, C. S., Keeth, S., \& Ryan, C. J. (2018). Collaborative Curriculum Design and Assessment: Piloting a Hybrid First-Year Writing Course. The University of Texas. 